\title{
Haemodynamic effects of sodium nitroprusside in 21 subjects with congestive heart failure ${ }^{1}$
}

\author{
STEVEN A. LUKES, CALIXTO A. ROMERO, JR. ${ }^{2}$, AND LEON RESNEKOV \\ From the Department of Medicine (Cardiology), The University of Chicago Pritzker School of Medicine, \\ Chicago, Illinois, USA
}

SUMMARY Twenty-one patients in severe congestive heart failure refractory to conventional medical management were treated with sodium nitroprusside on 22 occasions. On 14 occasions (responders) there was significant improvement in clinical and haemodynamic indices. On 8 occasions (non-responders) hypotension developed without haemodynamic improvement and nitroprusside treatment had to be abandoned. The initial mean arterial pressure and the capillary wedge pressure tended to be higher in the responders while the cardiac index tended to be higher in the non-responders. The systemic vascular resistance was higher in the responders than in the non-responders $(2560 \pm 160$ vs $1800 \pm 180$ dynes $\mathrm{s} \mathrm{cm}^{-5}, \mathrm{P}<0.001$ ). All of the responders had systemic vascular resistance greater than 1900 dynes $\mathrm{cm}^{-5}$, while only one of the non-responders had a systemic vascular resistance in this range. Thus, a variable response to vasodilator therapy for congestive cardiac failure is documented. The favourable response appears to be limited to patients with a high systemic vascular resistance.

Recent investigations have shown the effectiveness of vasodilator therapy in a number of clinical situations associated with severely impaired left ventricular function. Improvement has been shown in patients suffering from acute myocardial infarction with left ventricular failure (Franciosa et al., 1972; Chatterjee et al., 1973a), in those with severe mitral regurgitation (Chatterjee et al., 1973b), and in the treatment of chronic congestive heart failure refractory to the usual forms of treatment (Majid et al., 1971; Guiha et al., 1974; Miller et al., 1975).

The basis of this mode of treatment (Cohn, $1973 a, b)$ is a reduction of impedance to left ventricular outflow by lowering the resistance of the arteriolar bed and increasing the compliance of the large arteries. There is, in addition, venous vasodilatation and a consequent increase in venous capacitance; a reduction in ventricular preload follows (Cohn et al., 1972; Chatterjee et al., 1973a; Miller et al., 1975). The effects on the heart are a rise in ejection fraction as ventricular wall tension

${ }^{1}$ This work was supported in part by USPHS Grant, SCOR in Ischemic Heart Disease, and by the Chicago Heart Association.

${ }^{2}$ Present address: Medical Park Clinic, 100 Memorial Drive, Denison, Texas 75020, USA.

Received for publication 5 June 1978 declines, and a decrease in left ventricular size with an increase in stroke volume. The increase in cardiac output offsets the decreased systemic vascular resistance thus helping to maintain blood pressure at or near control levels. Myocardial oxygen is reduced since nitroprusside does not increase ventricular contractility or heart rate when used in the recommended manner.

Sodium nitroprusside has been used for this purpose because of its rapid action and high potency. Tachyphylaxis has not been noted with its use (Palmer and Lasseter, 1975). Certain safeguards are essential for its safe use, however, including measuring ventricular filling pressures, cardiac output, and systemic arterial pressure before and during its administration.

Despite its reported beneficial effects, the administration of sodium nitroprusside to patients in severe congestive failure in our coronary care unit (CCU) has, on occasion, been noted to result in a deterioration clinically as well as haemodynamically. Such deterioration occurs either acutely or even after a transient period of improvement. In this report we wish to document the varying haemodynamic responses in 21 patients who were treated with sodium nitroprusside on 22 occasions, in an attempt to provide guidelines for its safe use in the management of severe and often refractory congestive heart failure. 


\section{Subjects and methods}

Twenty-one patients, aged 16 to 76 years (mean 50 years) of whom 17 were men and 4 women, were studied. All were in severe congestive heart failure (NYHA Class IV) which had proved refractory to maximal conventional treatment using digoxin, diuretics, bedrest, and sodium restriction.

Symptoms of failure had been present for 1 to 6 years necessitating many admissions to hospital for all these patients. The causes of the congestive cardiac failure were: coronary heart disease in 7 (documented by cardiac catheterisation in 6); congestive cardiomyopathy in 14 (documented by cardiac catheterisation in 8).

After informed consent had been obtained the patients were studied in the CCU. A Swan-Ganz balloon-flotation catheter and a 'teflon' arterial catheter were inserted under local anaesthesia into the brachial vein and artery, respectively (Resnekov and Lipp, 1971). The pulmonary capillary wedge pressure or the pulmonary artery diastolic pressure were used to approximate the left ventricular filling pressure (Falicov and Resnekov, 1970). Cardiac output was measured in duplicate using the dye dilution technique. Systemic vascular resistance was calculated as:

$$
\frac{\text { MAP-RAP }}{\mathrm{CO}} \times 80 \text { dynes } \mathrm{s} \mathrm{cm}^{-5} \text { and }
$$

left ventricular stroke work index as:

SVI $\times($ MAP-LVFP $) \times 0.0144 \mathrm{~g} \mathrm{~m}$ per $\mathrm{m}^{2}$ where MAP is mean arterial pressure, RAP is right atrial pressure (both in $\mathrm{mmHg}$ ), SVI is the stroke volume in $\mathrm{ml}$ per $\mathrm{m}^{2}$ body surface area, and $\mathrm{CO}$ is the cardiac output in $1 / \mathrm{min}$.

After control measurements had been made, sodium nitroprusside was administered using an infusion pump starting with a dose of $0.5 \mu \mathrm{g} / \mathrm{kg}$ per min and increasing until a fall in blood pressure occurred. Cardiac output and pressures were measured again and the dose of nitroprusside titrated to maximise cardiac output without unduly reducing mean arterial pressure. The therapeutic trial was stopped if the systemic arterial pressure fell to $65 \mathrm{mmHg}$ or less or in patients in whom the cardiac output could not be increased without causing significant arterial hypotension. Otherwise treatment with nitroprusside continued for 2 to 7 days.

Treatment measurements contained in this report reflect those after 24 hours of nitroprusside infusion, unless the trial was stopped earlier, in which case the values shown represent the highest dose tolerated before the infusion was stopped. For purposes of analysis, patients were regarded as 'non-responders' if the therapeutic trial was stopped because of $\vec{\Rightarrow}$ hypotension. Patients were classified as 'responders' if an improvement in both clinical and haemo- $\frac{0}{0}$ dynamic indices was observed. When the patients $\frac{\bar{\sigma}}{\overline{0}}$ left hospital, those classified as responders were $\overparen{\Phi}$ prescribed regimens consisting of isosorbide di- 응 nitrate and, on occasion, hydralazine as well, in $\infty$ addition to continuing digoxin and diuretic therapy. $\vec{\circ}$

\section{Results}

Of the 21 patients studied, 13 showed a favourable clinical and haemodynamic response documented $\vec{i}$ by an increased diuresis, decreased symptoms, $\vec{\sim}$ lowering of the indirect left ventricular filling $\stackrel{\infty}{v}$ pressure associated with an enhanced stroke volume $ᄋ$ and cardiac index without tachycardia or hypoten- tion. This was sustained for at least 24 hours. Seven 7 patients, however, who failed to show any clinical $\frac{\mathbb{C}}{\mathrm{C}}$ or haemodynamic improvement were classified as non-responders. One patient (case 9) did respond favourably when studied first, but 18 months later $\vec{\theta}$ when restudied failed to respond clinically or 0 haemodynamically.

\section{RESPONDERS}

On 14 occasions there was a favourable response to the nitroprusside infusion, resembling that secn by several other observers (Guiha et al., 1974; Miller et al., 1975) (Fig. 1). Thus, nitroprusside reduced the systemic vascular resistance by 50 per cent or more (from $2560 \pm 160$ to $1070 \pm 80$ dynes s cm$~^{-5}$, 우 $P<0.001)$ while stroke volume $(29 \pm 3$ to $65 \pm 6$ 궁 $\mathrm{ml}, \mathrm{P}<0.001)$, cardiac index $(1.5 \pm 0.1$ to $3.0 \pm$ $0.201 / \mathrm{min}$ per $\mathrm{m}^{2}, \mathrm{P}<0.001$ ), and stroke work index $\left(14 \pm 2\right.$ to $30 \pm 3 \mathrm{~g} \mathrm{~m}$ per $\left.\mathrm{m}^{2}, \mathrm{P}<0.001\right)$ approximately doubled. Mean arterial blood pressure fell (from $98 \pm 4$ to $79 \pm 3 \mathrm{mmHg}, P<0.001$ ), while the average heart rate declined insignificantly (from $94 \pm 6$ to $84 \pm 5$ ). The indirect left ventricular filling pressure also fell by almost one-half (from $36 \pm 3$ to $21 \pm 1 \mathrm{mmHg}, \mathrm{P}<0.001$ ) (Table A).

These haemodynamic changes were accompanied of by evidence of clinical improvement in the cardiac $N$ failure and by an enhanced diuresis.

Follow-up of the patients which was maintained 0 for 2 to 24 months after the study revealed that 4 deaths occurred during this time, 3 of which were directly attributed to their cardiac disease.

\section{NON-RESPONDERS}

Treatment with nitroprusside was discontinued on 8 occasions because an improvement in cardiac output $\mathbb{\mathbb { D }}$ could not be achieved without compromising the $\frac{\Omega}{\sigma}$ blood pressure. On 7 occasions, there was a transient period of improved cardiac output and lowered 

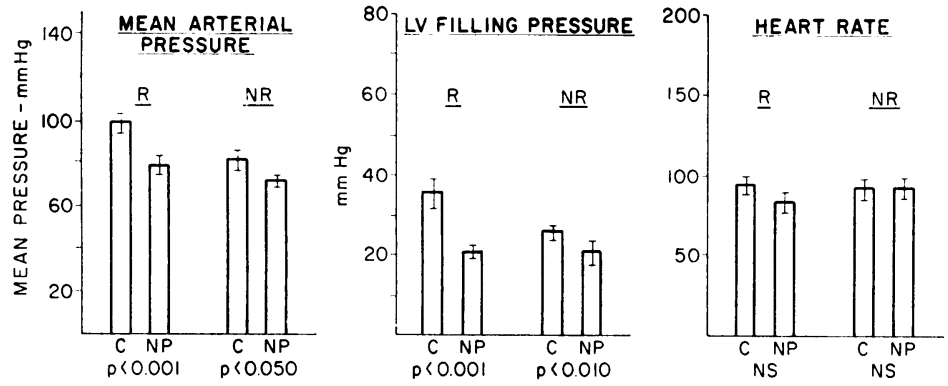

Fig. 1 Haemodynamic values during control $(C)$ and nitroprusside infusion (NP)

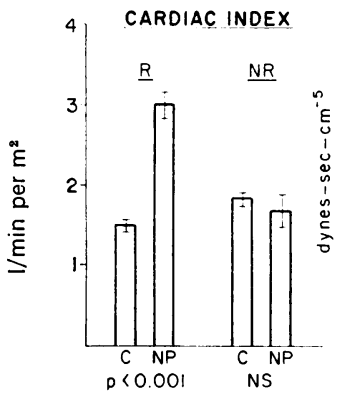

4000 SYSTEMIC VASCULAR

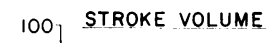
measurements in responders $(R)$ and non-responders $(N R)$.

le Summary of haemodynamic data

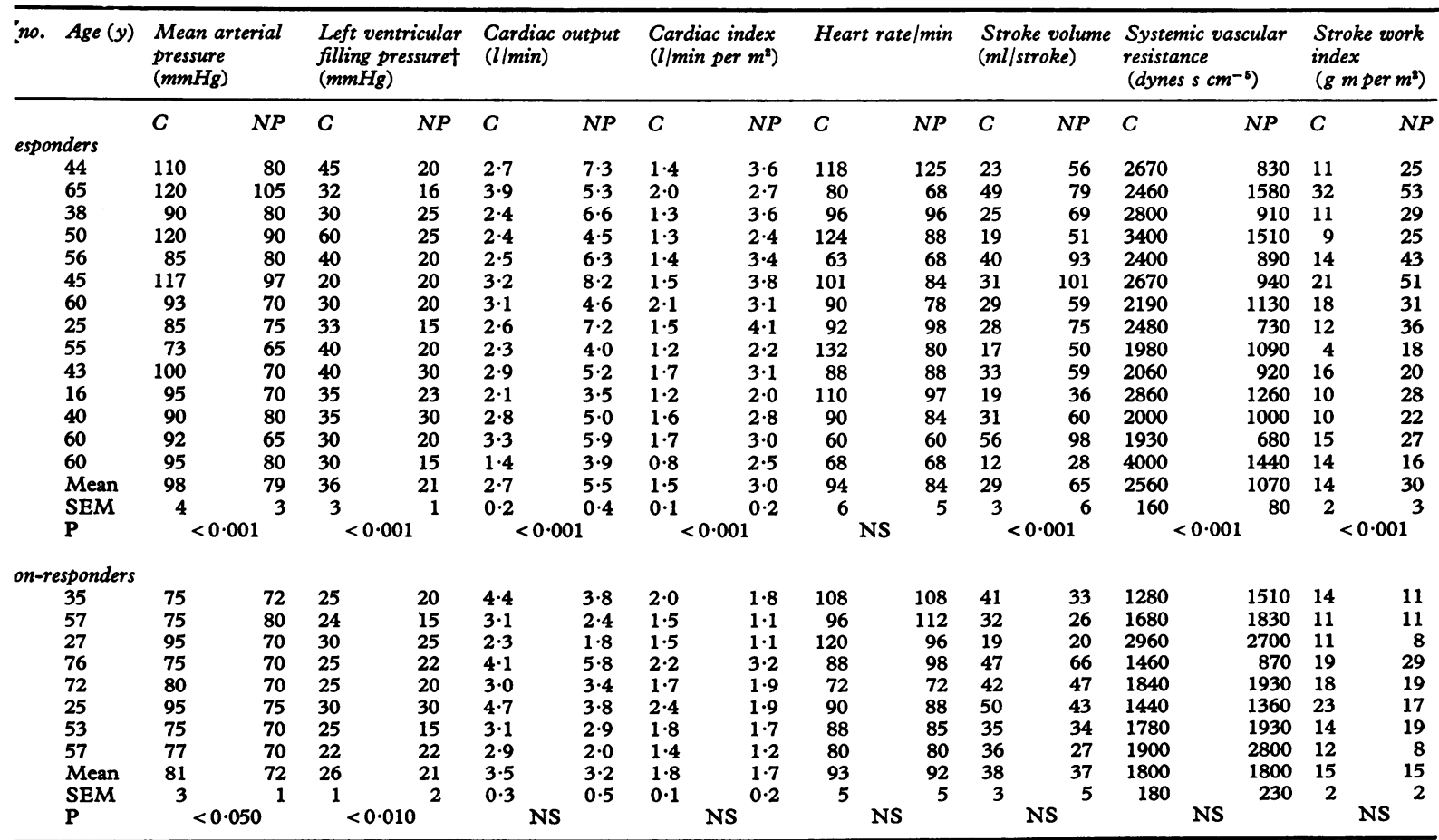

e 9 was studied on two separate occasions separated by an 18 -month interval. irect measurement. C, control; NP, nitroprusside. 
systemic vascular resistance, but thereafter (usually within 16 hours) the mean arterial pressure fell to unacceptable levels. Six patients had a decrease in cardiac output. Two patients (cases 18 and 19) experienced a modest increase in cardiac output which was insufficient to maintain the mean arterial pressure in the face of the decreased peripheral resistance. As a result, the group as a whole demonstrated no change in cardiac output, systemic vascular resistance, stroke volume, or stroke work index, despite a drop in arterial pressure from $81 \pm 3$ to $72 \pm 1(P<0.05)$ (Table B). The capillary wedge pressure also fell, from an average of $26 \pm 1$ to $21 \pm 2(P<0.01)$. Several of these patients subsequently required dopamine to maintain the blood pressure despite stopping nitro-
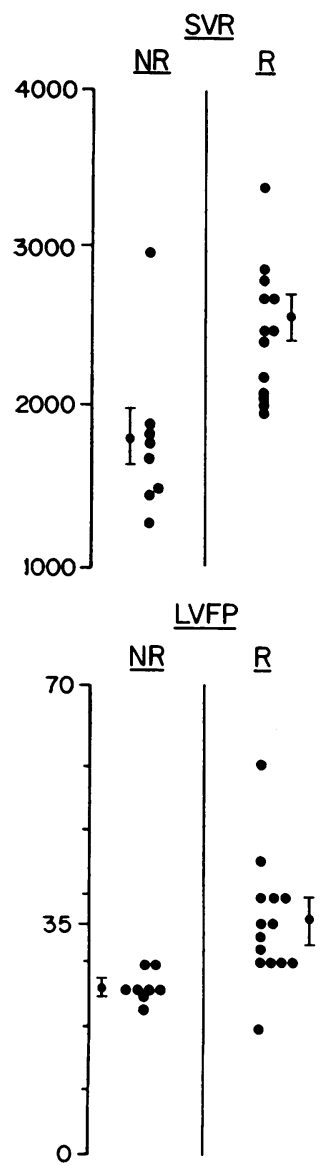
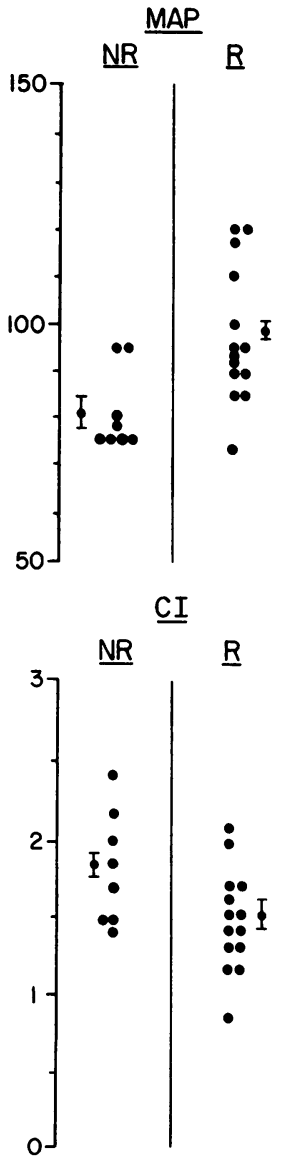

Fig. 2 Control haemodynamic values in non-responders $(N R)$ and responders $(R)$. SVR, systemic vascular resistance (dynes $\mathrm{s} \mathrm{cm}^{-5}$ ); MAP, mean arterial pressure $(m m H g) ; L V F P$, indirect left ventricular filling pressure $(m m H g) ; C I$, cardiac index (l/min per $\left.m^{2}\right)$. prusside. No patients experienced any untoward symptoms during the nitroprusside infusion (and no myocardial infarctions were documented).

Six of the non-responders died between 2 weeks and 2 months after study. All the deaths were attributed to cardiac failure and its complications.

\section{Discussion}

On the basis of the data obtained from the 21 patients studied it is recommended that when treatment with nitroprusside is being considered for the management of severe cardiac failure, particular attention should be paid not only to an assessment of left ventricular filling pressure but also to the level of the systemic vascular resistance.

Comparison of the control data for the two groups showed that they could not be distinguished on the basis of age, aetiology of failure, the physical signs, or by renal function. However, the haemodynamic data showed (see Fig. 2) that mean arterial pressure tended to be higher for the responders than for the non-responders $(98 \pm 4$ vs $81 \pm 3$, $P<0.005)$ as did left ventricular filling pressure $(36 \pm 3$ vs $26 \pm 1, P<0.005)$. Cardiac index tended to be higher for the non-responders $(1.5 \pm 0.1$ vs $1.8 \pm 0.1, P<0.005)$, while stroke volume and stroke work index were not significantly different between the two groups. There was, however, an overlap between the two groups making it difficult to predict the response in any individual patient. The systemic resistance was higher in the responders than in the non-responders $(2560 \pm 160$ vs $1800 \pm$ $180, P<0.01$ ) and, while all responders had a systemic vascular resistance greater than 1900 dynes $\mathrm{s} \mathrm{cm}-5$, only one non-responder had one in this range. Fisher's exact test (Brownlee, 1960) revealed the difference in systemic vascular resistance to be a significant prognostic indicator $(P<0.001)$.

Reports to date have emphasised the benefits of vasodilator therapy in congestive failure. The results obtained in this study suggest that there exists a group of patients in whom vasodilator therapy is not beneficial. An adverse response to nitroprusside has been noted to be associated with normal or low ventricular filling pressures in both acute myocardial infarction (Chatterjee et al., 1973a) and in chronic ischaemic heart disease (Miller et al., 1975). In this study the observations that the indirect left ventricular filling pressure tended to be higher in the group that responded to treatment supports the importance of assessing left ventricular filling pressure before and during treatment with nitroprusside. In none of our patients, however, did nitroprusside reduce the raised indirect left ventricular filling pressure to the normal range. 
The importance of knowing the systemic vascular resistance before using nitroprusside is shown by the fact that it was, in fact, the single most useful index for predicting the response. The raised systemic vascular resistance in those who respond favourably appears to be an inappropriate compensatory mechanism, the effect of which is to reduce cardiac output by increasing the afterload and thus opposing ventricular ejection. In contrast, however, in those who failed to respond to sodium nitroprusside, the systemic vascular resistance was closer to the normal range and attempts to reduce it were not associated with any improvement in the status of the patients. Thus, in those who do not respond to nitroprusside left ventricular dysfunction appears to be less dependent on afterload.

As shown by the haemodynamic measurements in the 21 patients congestive cardiac failure represents a heterogeneous syndrome. Ventricular filling pressure and systemic resistance vary greatly between patients and in the extent to which they compromise or support left ventricular function. Vasodilator therapy appears to be of most value in those in whom high afterload plays an important role in left ventricular dysfunction, and in whom ventricular filling pressures greatly exceed normal values.

The authors wish to express their appreciation for the invaluable assistance of the nursing and technical staff of the Coronary Care Unit.

\section{References}

Brownlee, K. A. (1960). Statistical Theory and Methodology in Science and Engineering. John Wiley, New York.

Chatteriee, K., Parmley, W. W., Ganz, W., Forrester, J., Walinsky, P., Crexells, C., and Swan, H. T. C. (1973a). Hemodynamic and metabolic responses to vasodilator therapy in acute myocardial infarction. Circulation, 48, 11831193.

Chatterjee, K., Parmley, S. S., Swan, H. J. C., Berman, G., Forrester, J., and Marcus, W. S. (1973b). Beneficial effects of vasodilator agents in severe mitral regurgitation due to dysfunction of subvalvular apparatus. Circulation, 48, 648690.

Cohn, J. N. (1973a). Blood pressure and cardiac performance. American fournal of Medicine, 55, 351-361.

Cohn, J. N. (1973b). Vasodilator therapy for heart failure. Circulation, 48, 5-8.

Cohn, J. H., Franciosa, J. A., Broder, M. I., Guiha, N., and Limas, C. J. (1972). Relative importance of preload and afterload as determinants of $\mathrm{LV}$ performance in acute myocardial infarction (abstract). Fournal of Clinical Investigation, 51, 20.

Falicov, R. E., and Resnekov, L. (1970). The relationship of the pulmonary artery end-diastolic pressure to the left ventricular end-diastolic and mean filling pressure in patients with and without left ventricular dysfunction. Circulation, 42, 65-73.

Franciosa, J. A., Guiha, N. A., Limas, C. J., Rodriguera, E., and Cohn, J. N. (1972). Improved LV function during nitroprusside infusion in acute myocardial infarction. Lancet, 1, 650-654.

Guiha, N. A., Cohn, J. N., Mikulic, E., Franciosa, J. A., and Limas, C. J. (1974). Treatment of refractory heart failure with infusion of nitroprusside. New England fournal of Medicine, 291, 587-592.

Majid, P. A., Sharma, B., and Taylor, S. H. (1971). Phentolamine for vasodilator treatment of severe heart failure. Lancet, 2, 719-724.

Miller, R. R., Vismara, L. A., Zelis, R., Amsterdam, E. A., and Mason, D. T. (1975). Clinical use of sodium nitroprusside in chronic ischemic heart disease. Circulation, 51, 328-336.

Palmer, R. F., and Lasseter, K. C. (1975). Sodium nitroprusside. New England fournal of Medicine, 292, 294-297.

Resnekov, L., and Lipp, H. (1971). Circulatory effects of acute myocardial infarction as a rational basis for therapy. Annals of Clinical Research, 3, 362-376.

Requests for reprints to $\mathrm{Dr}$ Leon Resnekov, The University of Chicago, Cardiology, Box 423, 950 East 59th Street, Chicago, Illinois 60637, USA. 